Check for updates

The BMJ

Cite this as: BMJ 2021;372:n217 http://dx.doi.org/10.1136/bmj.n217 Published: 22 January 2021

\title{
Covid-19: Reports from Israel suggest one dose of Pfizer vaccine could be less effective than expected
}

\section{Elisabeth Mahase}

Concerns have been raised over how much protection a single dose of the Pfizer BioNTech covid-19 vaccine provides, following reports from Israel that it is much lower than expected.

Israel, which, like the UK, is currently in its third national lockdown, has so far vaccinated more than $75 \%$ of its older people with at least one dose. Early reports from the vaccine rollout have suggested that the first dose led to a $33 \%$ reduction in cases of coronavirus ${ }^{1}$ compared with efficacy of at least $52 \%$ reported in clinical trials. ${ }^{2}$

A preliminary report from the Clalit Research Institute compared the infection data of 200 ooo people aged 60 and over who were not vaccinated with the infection data of 200 ooo people of the same age group who received one vaccine dose and were monitored for at least 11 days from the date of vaccination. On day 14 there was a "significant decrease of about $33 \%$ in the rate of positive tests for the coronavirus" among those who had been vaccinated. This decrease remained the same between days 15 and 17.

The report has raised concerns, as published results have suggested that the efficacy of the Pfizer vaccine was $52.4 \%$ between the first and second dose (spaced 21 days apart), and data assessed by Public Health England indicated it could be as much as $89 \%$ protective from day 15 to 21 .

The Clalit Research Institute stressed, however, that its results included only people aged 60 and over-whereas Pfizer trials also included younger people-and that the findings have not yet been peer reviewed. Additionally, the Clalit study identified those infected according to laboratory tests of those who chose to be tested, while Pfizer's studies only referred to the appearance of symptomatic disease.

In the UK, the vaccine policy prioritises getting as many at risk people vaccinated with one dose over ensuring people get two doses within the time specified in clinical trials. While there are data to suggest the chosen 12 week interval between the two doses is effective for the Oxford AstraZeneca vaccine, there are no data to support this interval for the Pfizer vaccine. $^{3}$

As such, a leading statistician has written to UK health secretary Matt Hancock urging him to investigate the effects of the decision to extend the gap between the first and second dose of the Pfizer BioNTech vaccine. ${ }^{4}$

On the reports from Israel, UK chief scientific adviser Patrick Vallance, in an interview with Sky News, said, "We know that when you get into real world practice, things are seldom quite as good as clinical trials. I don't know exactly what data Israel are looking at, but we need to look at this carefully."

Meanwhile, professor of pharmacoepidemiology at the London School of Hygiene and Tropical Medicine Stephen Evans said, "The UK will soon have its own data showing efficacy after the first dose for the different vaccines currently in use and any policy changes should await more robust data. If, for example, efficacy after one dose was $33 \%$ but efficacy after two doses was $60 \%$, the UK policy would still be justified. Similar arguments apply in relation to efficacy against serious disease."
Clalit study: decreased infection in the corona due to the vaccine. 13 January 2021. www.clalit.co.il/he/your_health/family/Pages/pfizer_covid_vac_ef- fect.aspx.
2 Mahase E. Covid-19: Pfizer vaccine efficacy was 52\% after first dose and 95\% after second dose, paper shows. BMJ2020;371:m4826. doi: 10.1136/bmj.m4826 pmid: 33310706
3 lacobucci G, Mahase E. Covid-19 vaccination: What's the evidence for extending the dosing interval?BM/2021;372:n18. doi: 10.1136/bmj.n18 pmid: 33408068
4 Mahase E. Covid-19: Assess the effects of extending Pfizer vaccine dosing interval, expert urges. BMJ 2021;372:n162. doi: 10.1136/bmj.n162 pmid: 33468515

This article is made freely available for use in accordance with BMJ's website terms and conditions for the duration of the covid-19 pandemic or until otherwise determined by BMJ. You may use, download and print the article for any lawful, non-commercial purpose (including text and data mining) provided that all copyright notices and trade marks are retained. 